\title{
Start-up research universities, high aspirations in a complex reality: a Russian start-up university case analysis using stakeholder value analysis and system dynamics modeling
}

Raafat M Zaini ${ }^{3^{*}}$, Dmitriy E Lyan ${ }^{1}$ and Eric Rebentisch ${ }^{2}$

\footnotetext{
* Correspondence: rzaini@wpi.edu ${ }^{3}$ Sociotechnical Systems Research Center, Massachusetts Institute of Technology, 77 Massachusetts Avenue, Cambridge, MA 02139, USA Full list of author information is available at the end of the article
}

\begin{abstract}
There have been several initiatives by the governments in different parts of the world to establish world-class universities (WCUs). Such initiatives have been attempted only several times and yielded varied results. This article contributes to the existing body of research in architecting WCUs by presenting an operational strategic modeling framework that is grounded in the existing body of literature for developing WCUs (Salmi 2009) which can be used to test assumptions, reveal strategic levers, and analyze dynamic complexity inherent in a task of scaling a start-up university. We present a research study that leveraged stakeholder analysis and system dynamics modeling to architect and test a long-term strategic plan of scaling a newly created Skolkovo Institute of Science and Technology (SkolTech) in Moscow, Russia. We find that the existence of patient capital and favorable governance is conditional on university leadership's ability to effectively manage stakeholder expectations, maintain high-quality standards of its faculty and student population, and protect its brand of a world-class institution. We argue that the operational framework and findings derived from the case of SkolTech can be generalized and applied to other efforts in that area.

Keywords: Strategy; Higher education; Modeling and simulation; System dynamics; Economic development; Innovation; Entrepreneurship
\end{abstract}

\section{Springer}

(c) 2015 Zaini et al.; licensee Springer. This is an Open Access article distributed under the terms of the Creative Commons Attribution License (http://creativecommons.org/licenses/by/4.0), which permits unrestricted use, distribution, and reproduction in any medium provided the original work is properly credited. 
Spanish: Universidades de investigación de nueva creación, grandes aspiraciones en un entorno complejo: el análisis de una universidad rusa de nueva creación empleando el Análisis de Valor de Grupos de Interés y el Modelado de Dinámicas de Sistema.

Resumen: En diversos lugares del mundo, algunos gobiernos han emprendido iniciativas con el propósito de crear universidades de "categoría mundial" (más adelante denominadas WCU, del inglés World Class Universities). Dichas iniciativas se han llevado a cabo en contadas ocasiones y con resultados muy diversos. Este artículo es una contribución al corpus de investigación existente en torno a la creación de universidades de "categoría mundial" y presenta un marco de modelado estratégico operacional basado en el corpus de literatura existente en relación con el desarrollo de WCU (Salmi, 2009), el cual puede ser empleado para validar hipótesis, revelar palancas estratégicas y analizar la dinámica complejidad inherente que supone escalar un universidad de reciente creación. Presentamos un estudio de investigación que empleó el análisis de grupos de interés y el modelado de dinámicas de sistema para diseñar y ensayar un plan estratégico a largo plazo para escalar el recientemente creado Skolkovo Institute of Science and Technology (SkolTech) en Moscú, Rusia. Hallamos que la disponibilidad de "capital paciente" (patient capital) y un gobernanza favorable influyen en la capacidad de liderazgo de la universidad para gestionar de manera efectiva las expectativas de los grupos de interés, manteniendo unos estándares de calidad elevados tanto entre el personal universitario como entre los estudiantes, a la vez que protege la marca de una institución de "categoría mundial". Sostenemos que el marco operacional y los hallazgos derivados del caso SkolTech pueden ser extendidos y aplicados a otras iniciativas dentro de la misma área.

French: Les Universités de Recherche Startup, des aspirations élevées et une réalité complexe: Etude de cas d'une Université Startup Russe, par l'analyse de valeur des Stakeholders et la modélisation des dynamiques de système.

Résumé: De nombreux gouvernements dans le monde ont pris à plusieurs reprises des initiatives pour établir des Universités de classe mondiale (WCU). Ces initiatives ont eu des résultats très variables. L'article contribue au corpus existant de recherches qui visent à structurer les universités de classe mondiale, en présentant un cadre de modélisation stratégique opérationnel basé sur le corpus existant de littérature sur le développement des WCU (Salmi, 2009), qui peut être utilisé pour tester des hypothèses, découvrir des leviers de croissance, et analyser la complexité dynamique inhérente au développement des Universités Startup. II présente une recherche qui utilise l'analyse des Stakeholders et la modélisation dynamique pour concevoir et tester un plan stratégique à long terme pour le développement de I'Institut Skolkovo de la Science et de la technologie (SkolTech) de Moscou en Russie. Les auteurs constatent que l'existence de capitaux d'investissement à long terme et une gouvernance favorable sont des conditions nécessaires pour que l'université puisse gérer les attentes des Stakeholders, maintenir des normes de qualité élevées pour son corps professoral et sa population étudiante et tenir son rang d'institution de renommée mondiale. Les auteurs démontrent que le cadre opérationnel et les conclusions que l'on peut tirer du cas de SkolTech peuvent être généralisés et appliqués à d'autres efforts dans ce domaine, 
Russian: Стартапы исследовательских университетов - высокие запросы в сложных условиях: анализ приоритетов заинтересованных лиц и моделирование динамики системы на примере университетских стартапов России

Абстракт: Известен ряд инициатив, реализуемые правительствами в различных частях света, направленных на создание университетов международного уровня (World Class University). Подобные попытки предпринимались всего несколько раз и привели к различным результатам. Настоящая статья делает вклад в существующие исследования, посвященные проектированию университетов международного класса, представляя рабочую стратегическую модель, которая основана на систематизации значительного объема релевантных проблематике WCU (Salmi, 2009) и может быть использована при подборе допущений, раскрытия стратегических инструментов управления и анализа динамической сложности, опосредованно возникающих при масштабировании университетских стартапов. Мы представляем результаты исследования, в котором проведены оценка заинтересованных лиц и моделирование динамики системы с целью проектирования и испытания долгосрочного плана по масштабированию вновьсозданного Сколковского Института Науки и Технологии (Сколтех) в г.Москва, Россия. В ходе исследования было обнаружено, что наличие «терпеливого» капитала и благоприятного управления способствует конкурентоспособности университета в удовлетворении ожиданий заинтересованных лиц, поддержании высоких стандартов качества преподавателей и студентов и поддержке собственного бренда университета мирового класса. Мы считаем, что рабочая модель и выводы, полученные на основе изучения опыта работы Сколтеха, могут быть обобщены и использованы в решении аналогичных задач в смежных областях.

Chinese: 在复杂现实中志存高远的新创研究型大学: 通过利益相关者价值分析和 系统动力学建模分析俄罗斯新创大学的案例

摘 要: 在这个世界上的不同地区已经由政府发起动议一一创建世界一流大学 (world class university, WCU)。只有若干这样的动议被尝试付诸实践, 并取得了 不同的结果。本文对于现阶段研究的主要贡献在于:基于发展世界一流大学的现 有文献(Salmi,2009)提出可操作的战略模型框架。利用这个框架能验证假设、发 现战略杜杆和分析衡量一所新创大学工作固有的动态复杂性。我们提出利用利 益相关者分析和系统动力学建模来构造和检验 SkolTech的长期战略计划,

SkolTech 即新建于俄罗斯首都莫斯科的斯科尔科沃科技学院的简称。研究发现 充裕的资本和良好的治理是高校领导能有效管理利益相关者所期望的东西一 即保持高质量标准的教师和学生数并维护世界一流大学品牌一一的条件。我们 坚信, 由SkolTech的案例而来的操作框架和研究发现在世界范围内具有广泛的推 广性和应用性。 
Portuguese: Universidades Startup de Pesquisa, aspirações elevadas em uma realidade complexa: Analise de caso da Universidade Startup Russa usando a análise de valor do Stakeholder e modelagem de sistemas dinâmicos.

Resumo: Em diferentes partes do mundo, houve várias iniciativas por parte dos governos, para estabelecer world class universities (WCU). Tais ações foram tentadas diversas vezes e renderam resultados variados. Esse artigo contribui com o conjunto de estudos acerca da pesquisa que visa estruturar World Class Universities apresentando uma estrutura de modelagem da estratégia operacional que é baseada na literatura existente sobre o desenvolvimento das WUCs (Salmi, 2009), a partir da qual se pode testar hipóteses, revelar as estratégias de crescimento e analisar a complexidade dinâmica inerente às tarefas de crescimento de uma universidade startup. Apresentamos uma pesquisa que utilizou a análise dos stakeholders e um sistema de modelagens dinâmicas para construir e testar o plano estratégico no longo prazo para ampliação do recém-criado Skolkovo Institute of Science e Technology (SkolTech) em Moscou, Russia. Encontramos que a existência de capital para investimento no longo prazo e uma governança favorável são condicionantes favoráveis na habilidade da liderança para gerir de forma eficaz as expectativas dos stakeholders, manter o alto padrão de qualidade do seu corpo docente-estudantil e manter sua marca de instituição de classe mundial. Argumenta-se que a estrutura operacional e as conclusões resultantes no caso da SkolTech podem ser generalizadas e aplicadas a outros esforços nessa área.

\section{Multilingual abstract}

Please see Additional file 1 for translation of the abstract into Arabic.

\section{Introduction}

The Skolkovo Institute of Science and Technology (SkolTech) is a private graduate research university in Skolkovo, Russia. It was established in 2011 as an initiative to integrate Russian scientific capabilities with entrepreneurship and innovation as a means of increasing the dynamism and diversity of the Russian macro economy. It has been developed in collaboration with the Massachusetts Institute of Technology (MIT) and is supported from MIT by the MIT SkolTech Initiative. It is unique in its mission and setting - create an equivalent Cambridge MA or Silicon Valley on the outskirts of Moscow - with its combination of world-class research university and vibrant entrepreneurship community coexisting symbiotically. Partnering with MIT enabled SkolTech to leverage a proven path of world-class research and innovation. SkolTech chose to develop five primary education and research programs, corresponding with Russian technology priority areas: Information Science and Technology, Energy Science and Technology, Biomedical Science and Technology, Space Science and Technology, and civilian Nuclear Science and Technology. Graduate degrees are granted in each of these areas.

The case of SkolTech is an opportunity to explore and understand how complex educational systems in their start-up phase behave and evolve in light of the research done in this area. For the researchers, this is a fascinating opportunity to apply tools for analysis and understanding that are themselves in the early stages of their development and are continuously evolving.

The role of research universities in transforming the economy

Over the past century, science and technology universities played an integral role in the innovation, economic development, and prosperity of a region or country (Chameau 
2013; Etzkowitz 2002). Therefore, research universities' roles extend from educating world-class scientists and engineers to providing the social environment for their students and faculty to create and nurture ideas with commercialization and entrepreneurial value (Hsu et al. 2007). It was found, for instance, that the 25,800 companies founded by MIT alumni employ about 3.3 million people and generate annual world sales of $\$ 2$ trillion, producing the equivalent of the eleventh-largest economy in the world (Hsu et al. 2007). These companies create growing markets for utilities, service firms, retailers, and other local-market businesses.

Many assume a straight path from science produced in universities and research labs to innovation to manufacturing but often neglect the time between realizing the fruits of scientific discovery and resulting economic activity (Gokhberg and Meissner 2013). Nonetheless, to guide countries in transforming their economies to become knowledge-based, there are four key strategic dimensions that must be present: an appropriate economic and institutional regime, a strong human capital base, a dynamic information infrastructure, and an efficient national innovation system (Salmi 2009, p. 2).

The role of research universities is evident in training the needed professionals, highlevel specialists, scientists, and researchers to generate new knowledge that supports national innovation systems (Salmi 2009, p. 2). However, a diverse suite of institutions each with different roles like research universities, polytechnics, liberal arts colleges, short-duration technical institutes, community colleges, open universities, and the like are needed to produce the range of skilled workers needed by the labor market for it to function properly and achieve the needed development balance (Salmi 2009, p. 2).

\section{SkolTech as a change driver}

Russia, while working on its transformation into a market economy, still depends highly on its export of natural resources and lacks an internal mechanism for sustainable growth (Gokhberg and Roud 2012). Despite Russia's long history of scientific and technological breakthroughs, the available high-quality human capital and scientific potential (Graham 2013) is trapped in the Soviet tradition of keeping research separate from both enterprise and universities (Gokhberg and Meissner 2013). The Soviet Union at the time prohibited the entrepreneurial capitalism in fear of entrepreneurs rising as power rivals (Graham 2013, pp. 161-162). Graham (2013, p. 135) also argues that the Russian universities were misled by the development of the research university model in Europe in the early twentieth century that focused only on research without education which the American universities that followed that model soon abandoned. Russia persisted on following that model and invested heavily in creating the Russian Academy of Sciences and its affiliated research-only institutions, thereby creating a rift between teaching and research which, according to some prominent American scientists and academic administrators, is a wrong move as teaching actually prevents stagnation and stimulates research and its applications by bringing fresh ideas through the influx of students over the years (Graham 2013, p. 137).

In 2010, then-president Dmitry Medvedev declared 'We have money but we don't have our Silicon Valley' (Saltykovsky 2013) and gave orders to create an innovative center, Skolkovo, to develop a Russian new economic policy (Kinossian and Morgan 2014). SkolTech, a new university with a focus on education and research established in partnership with MIT under the umbrella of Skolkovo, is envisioned to be one of the 
biggest tech innovation and entrepreneurship centers in the world (Saltykovsky 2013). Creating a new world-class research university, in addition to upgrading or merging existing ones (Gokhberg and Roud 2012; Salmi 2009, p. 43) despite the difficulties involved in the culture change process (Salmi, 2009, p. 9) reflects Russia's high ambitions for accelerating innovation facilitated by its current abundant financial resources.

SkolTech is intended by the highest leadership of the country to give 'a shot in the arm' to the Russian technology industries (Saltykovsky 2013). Government officials hope that SkolTech becomes a 'factory' of new faculty that percolates through all Russian universities and affects change with their new, innovative ideas. The Moscow government hopes that SkolTech will focus on bringing value to the local area by leveraging its engineering component. The aspiration is that other cities in Europe and around the world will recognize SkolTech as a center for technological expertise if SkolTech is able to catalyze visible results in solving major city problems in Moscow.

SkolTech is expected to facilitate access to international talent and research projects and become a major player in the development of an innovation ecosystem and an institution that will prepare students to perform this type of work that will help Russia to become competitive in innovation. In a recent visit to SkolTech to attend the second international start-up village conference, prime minister Medvedev expressed his government's unwavering support for Skolkovo saying that 'there will be an innovation center and there will be a university -Skoltech' (Newsletter SkolTech 2014). The display of support by Medvedev for SkolTech is worrisome as it does not seem to be shared by president Putin who asserted that SkolTech is not the only the scientific institution in Russia that deserves government support following a veto for its onceapproved exemption from the need to obtain planning permits (Plutocrat Vs. Tech-nocrat 2013). The public also has a skeptical stance towards the new institution as another government corruption venue to stifle the country's financial resources under a noble cause to those in power and their partners, including and not limited to MIT and the involved corporate entities accusing them of seeking their own benefits in the form of tax exempts and improved access to Russia's talent and markets (Kinossian and Morgan 2014; Plutocrat Vs. Tech-nocrat 2013). Others, including existing universities and energy sector advocates, see the mega spending on SkolTech is money squandered (Kinossian and Morgan 2014). To avoid being in the crossfire between governmental and special interest entities, SkolTech needs to have a robust autonomous governance structure and a high degree of transparency (Salmi, 2009) like its partner MIT and many world-renowned institutions. For SkolTech to disprove this skepticism and succeed, it needs to build large-impact businesses and make more money than what it spends as close sources to Skolkovo assert (Saltykovsky 2013). But how will the public realize its societal impact of open and accelerated innovation if it is placed in a gated community with very strict security protocols that isolates it from its surroundings (Kinossian and Morgan 2014)?

Graham (2013) suggests that Russia's attempts to regenerate the research sector by attracting high-level scientists, upgrading equipment, and making greater use of talented students provide the basis for innovation, and there are signs for the appearance of high-tech entrepreneurship in the country. Government intervention to support the national innovation system and university innovation in particular has resulted in multiple success stories, such as spin-off companies and growth in private venture 
investments (Gokhberg and Meissner 2013). But the socioeconomic outcomes are too early to be judged (Gokhberg and Roud 2012) because the road to be traveled is long and the changes need to be spread more widely, as expressed by one of the SkolTech members of the board of trustees ${ }^{\mathrm{a}}$ in a recent interview. However, with a main emphasis on technology and tangible measures (Kinossian and Morgan 2014) rather than societal change, the outcomes might not be auspicious and the government's current enthusiasm and support might just be a spasm (Graham 2013, p. 161) that will diminish over time simply by a change of leadership or priorities. The government's high expectations from SkolTech to have a quick and huge impact and its dependence on government support makes SkolTech's future to deliver what it is designed to do too vulnerable to exogenous shocks that may result from unforeseeable changes in the turbulent political landscape (Kinossian and Morgan 2014).

\section{The MIT idea}

A key element of SkolTech's development is the decision by the Russian government to partner with MIT in the US to help in the creation of SkolTech. Given the central role that MIT was intended to play in SkolTech's development, it is instructive to explore past experiences involving MIT partnerships with nations to develop technical universities and accompanying innovation ecosystems.

MIT exemplifies the latest step in the evolution of universities from the medieval higher education institution concerned with the conservation of knowledge to the entrepreneurial university with the purpose of capitalization of knowledge by combining research and teaching with industrial innovation that has an impact on regional economic development (Etzkowitz 2002). This entrepreneurial model was championed by MIT vice-president Vannevar Bush and then transferred to Stanford University after the second world war through one of his PhD students, Fredrick Terman, who became a provost there (Etzkowitz 2002). Since the 1950s and shortly after it redefined engineering education, MIT's overall strategy was and still is to become a global institution that has deep ties with research partners around the globe (Leslie and Kargon 2006). Its focus on entrepreneurship was evident in the start-up companies that populated Route 128 which encouraged its champions to market that model to the developing world. The overarching mental model was '...that modern engineering, like modern capitalism, was essentially global and linear. The less-developed would advance by learning from, and emulating, the more-developed' (Leslie and Kargon 2006). Despite all the enthusiasm, MIT's experience in exporting its educational model to other parts of the world came with mixed results and seems to have evolved over time. India, Iran, Portugal, Britain, and Singapore are among the countries MIT was involved in, and a brief discussion of its experience in those places is relevant to this topic.

As per the Indian government's wish to build a world-class institution with a surrounding environment similar to Boston or Stanford, MIT was involved in India during the 1960s to establish two universities. The Indian Institute of Technology (IIT) at Kanpur was architected along the lines of the MIT way of promoting engineering sciences and preparing scientists and engineers for jobs that could exist only in the US or Europe. IIT Kanpur succeeded in becoming a world-renowned educational institution that exports $80 \%$ of its computer science graduates to the US. This was seen to 
have accelerated, in the short term, the brain drain from India rather than having curtailed it (Leslie and Kargon 2006), but according to a recent study, this brain drain declined to $40 \%$ and is reversed, contributing to the emergence of India technological and entrepreneurial spirit and its economic growth (Salmi 2009, p. 46). The second university was the Birla Institute of Technology and Science (BITS) which, based on its founder's vision ${ }^{\mathrm{b}}$, had a local focus to develop field and plant application engineers taking responsibility to identify and execute solutions in the Indian society with Indian materials and workmen (Leslie and Kargon 2006). BITS successfully helped in educating India's top industrialists and engineers and kept its graduates in India at the expense of a lower international profile.

In Iran, during the Shah's reign in the 1970s, the Aryamehr University of Technology (AMUT) was established with the help of MIT to be at the forefront of technical education, using approaches that even MIT did not introduce into its curriculum for a decade. It encompassed state-of-the-art interdisciplinary research centers that transcended traditional academic departments (Leslie and Kargon 2006). The AMUT mission was to indigenize technology in Iran and not simply to copy it from the west, and to train a group of elite engineers who could compete at international levels without abandoning their cultural values and could become key instruments in the future of economic and social development of Iran. The university delivered on its promise by graduating topnotch engineers but also became an active host for the Islamic revolution. AMUT exceeded initial expectations despite being split into two universities (Sharif University of Technology in Tehran and Isfahan University of Technology) which played a key role in Iran industrialization both in civil and defense technologies, a continuous yet disputed brain drain to the developed world.

The MIT-Portugal Program (MPP) launched in 2006 for a 5-year duration demonstrated a specific collaborative strategy to stimulate critical changes in strategic focus areas in Portugal's leading institutions (Pfotenhauer et al. 2013). The program focused on raising the standards for student internationalization and selectivity rates, building national clusters of excellence, and reorienting engineering education towards innovation and entrepreneurship. The government intervention took the path of upgrading current institutions to foster communication between them rather than creating from-scratch universities to induce change (Salmi 2009). MIT played an active role in moderating the relationship between the universities, research institutes, and the local industry in addition to teaching students, training faculty, and designing new educational programs. The collaborative program has proven to be a successful policy instrument and a model strategy for building human resources, research, and innovation suited for long-term economic growth. It was capable of seeding reform at key elements in the Portugal higher education system despite being under budgetary and time constraints. Five years is a short duration in which to cause measurable changes in higher education systems (Pfotenhauer et al. 2013). MPP avoided the pitfalls of brain drain by emphasizing the national identity of the program honoring degrees by Portuguese institutions and the 'sandwich mobility anchor strategy' that allowed students to spend an intermediate period during their course of study at MIT after which they had to return back to Portugal to earn their degrees (Pfotenhauer et al. 2013). There are many interesting details about the program strategy, execution, and outcomes that go beyond the scope of this work and could be found in the cited reference (Pfotenhauer et al. 2013). 
In its attempt to become a knowledge economy, the Singapore government started the Global Schoolhouse platform and launched the Singapore-MIT Alliance (SMA) with an articulated aspiration to become the 'Boston of the east' (Sidhu et al. 2011). The alliance involved Singapore's two national universities, the National University of Singapore (NUS) and the Nanyang Technological University (NTU). It was devised to promote entrepreneurial engineering education and trans-nationalization (Ka Ho 2008) in the city-state. The MIT brand was leveraged to serve that purpose and to attract many international students to study in Singapore. MIT took the lead role in creating the master's degree curriculum and participated in the $\mathrm{PhD}$ program design too. It also facilitated joint research between its faculty and their Singaporean counterparts. MIT did not have to endure any financial risks running this experiment as the cost was totally borne by the government of Singapore. For MIT, a presence in the dynamic Asia region bustling with economic growth and a plethora of international students would provide it with future collaborative opportunities to maintain its global prestige and financial superiority. The program met many of its performance indicators with respect to student enrollment, PhD completion, and patents and publications (Sidhu et al. 2011). However, its success in generating technopreneurs is less clear given the long time delays needed for entrepreneurial activities to emerge and flourish. Indicators show that fewer graduates chose to become entrepreneurs and leave safer career choices in academia and industry. Some alumni refer to a broader social context which does not encourage failure, an essential virtue for stimulating and sustaining the entrepreneurial spirit. The assumptions made by the policymakers regarding this type of collaborative effort might explain the gap between their high expectations and the observed outcomes. The government assumed that research and development is portable independent of any local context and can be shipped from one region to another once the resources are there. The other assumption is that researchers are rational actors and can seamlessly fit into any part of the world and effectively function across borders. In fact, MIT faculty neither relocated to Singapore nor stayed for prolonged periods. Singapore, despite its relentless policy fine-tuning, continues to face challenges in its endeavor to retain world-class foreign talent - established innovators and knowledge entrepreneurs (Ka Ho 2008).

A transatlantic experimental collaboration program of a different flavor was initiated between two leading western industrial economies sharing many cultural similarities, the UK and the US. A 5-year program was initiated in the year 2000 by the UK government and championed by then counselor Gordon Brown to link one of the top British universities, Cambridge University, with MIT to help transform research into commercial enterprises (Vandre 2003). The focus was to address perceived issues like the lack of management skills and weak industry-university links in the UK academic institutions, which were perceived as deficiencies in the UK innovation system (Simmonds et al. 2009). The initiative resulted in the Cambridge-MIT Institute (CMI), a joint education and research partnership focusing on encouraging entrepreneurship, increased productivity, and competitiveness through coordinated research and faculty and student exchange (Cambridge, MIT join forces: Universities promote U.K. entrepreneurship 1999). The UK government had very high expectations from the initiative, predicting hundreds of new businesses as outcomes form this partnership (MIT, Cambridge join forces: Final Edition 1999). The program underperformed in its early 
years, which led to a leadership change (Adam 2002) resulting in sharpening the program focus and improving its monitoring and evaluation levels, especially the ones related to the consideration of use (Simmonds et al. 2009). The evaluation of the program, however, came with mixed results (Simmonds et al. 2009). The program achieved its objectives in the broader sense of delivering excellent education and research programs with good innovation potential and measurable economic impacts to both partners. Its commercialization outcomes, on the other hand, were comparable to the aggregated average performance of the UK universities with fewer-than-anticipated numbers of spinouts (Simmonds et al. 2009). It was also less successful in running as an experiment to test the CMI model and to systemize the know-how of managing multilateral and interdisciplinary cooperation across borders. MIT senior managers came to recognize, to their surprise, that there is not only one way of excellence and '...a research university can achieve and sustain world-class performance through an approach that is radically different from the "MIT way", 'which contributed slightly to a different approach towards future international partnerships (Simmonds et al. 2009).

The preceding accounts suggest that MIT's approach was constantly evolving over time, trying to learn from its past experiences and adapt its idea of engineering education and entrepreneurship. However, its partners ultimately have the final responsibility for long-term entrepreneurial performance. MIT cannot influence the vision and aspirations of a nation, but it can help guide them through the process according to its own evolving approach. The cultural, social, and political challenges that MIT was committed to overcome through modifying its ideas and offering alternatives to accommodate the goals and resources of its partners seem to be harder than expected. It helped found institutions embedded in part with American experiences and expectations, as in the cases of India and Iran, that potentially put them and their graduates in conflict with their economic and political realities (Leslie and Kargon 2006). Achieving research synergies between institutions in countries with vastly different histories, missions, and trajectories presents many challenges, not all of which can be surmounted by generous funding and access to state-of-the art technological equipment. Policymakers need to re-imagine scientists, engineers, technopreneurs, and higher education entrepreneurs as complex human actors who are embedded in specific cultural and social contexts (Sidhu et al. 2011).

According to SkolTech plans and objectives, SkolTech is an independent private science and technology university seeking to attract and educate talented students from Russia and abroad. It is planned to have 1,200 graduate students, 200 professors, and 300 post docs by the end of the decade. It is considered a small university with a student to faculty ratio of 6:1 close to California Institute of Technology (Caltech) in the US, which maintains the lowest number of $3: 1^{c}$. It strives to make a global impact on the supply of talent through education, on the body of knowledge through scholarship, and economic development through innovation and entrepreneurship. It is planning to accomplish that by working closely with local and international partners, and MIT comes on top of that list. Its main funding source comes from the Russian government through a nonprofit Skolkovo foundation. According to the founding document of Skoltech, it is interesting to know that MIT was founded to partially emulate the model of the "Russian School" of engineering education at the Moscow State Technical University, founded in 1830, i.e. 31 years before MIT was founded. 
The SkolTech partnership with MIT shares many attributes from previous MIT collaborations with national universities as shown in Table 1. It is a top-down government initiative that is generously funded. It involves building an institution from the ground up like the case in India and Iran with a focus on creating a Boston-like environment. This focus was also shared with Singapore, UK, and to some extent the IIT Kanpur in India. The interdisciplinary nature of SkolTech academic programs is a signature of MIT philosophy in engineering education which was implemented in Iran, Portugal, Singapore, and the UK. MIT's past experience with building new universities included both undergraduate and graduate programs, unlike the case of SkolTech which is solely a graduate university. Similar to the Cambridge MIT initiative, this is a partnership with an industrialized country that has a great pride in its deep scientific and cultural heritage. The most interesting feature in this partnership, however, is that it is between two institutions located in two countries who still are the world's superpowers in the contemporary history and who have totally different views of the world.

\section{An ambitious experiment in a complex reality}

SkolTech, like other start-up research universities, involves closely watched experiments designed, executed, and managed by academics and administrators from elite western higher education institutions like MIT. Their local governments have high trust in these institutions to help safely guide the fledgling universities to their aspired future. Although many universities, as shown in the previous section, were established with high expectations for leading innovation, creating industries, and achieving longterm technological and economic development, not all of them became or will become a local version of Silicon Valley (Chameau 2013). This is largely because success of commercial technology depends on factors that exist outside the laboratory, such as politics, social barriers, investment climate, corruption, etc. (Graham 2013). Hence, the degree of institutional effectiveness and impact on the innovation and prosperity of a region varies significantly due to the complexity of the issue at hand.

According to Chameau (2013), many factors contribute to the success of such initiatives including but not limited to the educational ecosystem that involves not only the institution of concern but the network of research universities and colleges that provide the education and manpower needed to propel the knowledge-driven economy. Other factors relate to disciplinary focus, collaboration with national and international partners, and the supporting culture for technology transfer. The most important factors may involve the presence of institutional environments that support both curiositydriven research as well as problem-driven research. The latter is short-term focused and gratifying while the former is long-term and risky but delivers great discoveries with the most dramatic impact. When this is combined with an agile operational structure that welcomes interaction with diverse stakeholders in the economic arena, a success-reinforcing culture materializes to perpetuate success. For instance, the overall MIT entrepreneurial ecosystem, consisting of multiple education, research, and social network institutions and phenomena, contributes to the outstanding and growing entrepreneurial output mentioned earlier. However, this ecosystem evolved over 150 years promoting the culture of 'Mens et Manus', or 'mind and hand' (Roberts and Eesley 2011). Chameau (2013) also emphasizes the experimental nature of the new 
Table 1 Key attributes of MIT partnerships around the world

\begin{tabular}{|c|c|c|c|c|c|}
\hline Partnership & Change strategy & Economic development focus & $\begin{array}{l}\text { Education } \\
\text { programs }\end{array}$ & Funding source & Overall outcomes \\
\hline $\begin{array}{l}\text { India ( IIT } \\
\text { Kanpur) }\end{array}$ & Building a world-class institution from scratch & Boston and Silicon Valley & $\begin{array}{l}\text { Undergraduate } \\
\text { and graduate }\end{array}$ & USAID & $\begin{array}{l}\text { World-class institution with high brain } \\
\text { drain }\end{array}$ \\
\hline India (BITS) & Building an institution from scratch & $\begin{array}{l}\text { Technology for serving local } \\
\text { needs by local people }\end{array}$ & $\begin{array}{l}\text { Undergraduate } \\
\text { and graduate }\end{array}$ & Ford Foundation & $\begin{array}{l}\text { Influential player in industrialization, no } \\
\text { world-class status and no brain drain }\end{array}$ \\
\hline Iran (AMUT) & Building a world-class institution from scratch & $\begin{array}{l}\text { World-class technical expertise } \\
\text { with national focus }\end{array}$ & $\begin{array}{l}\text { Undergraduate } \\
\text { and graduate }\end{array}$ & Government & $\begin{array}{l}\text { Influential player in technological } \\
\text { development with world-class status } \\
\text { and brain drain }\end{array}$ \\
\hline $\begin{array}{l}\text { Portugal (MIT- } \\
\text { Portugal } \\
\text { Program) }\end{array}$ & Collaboration between existing institutions & $\begin{array}{l}\text { Innovation and entrepreneurship } \\
\text { with national identity focus }\end{array}$ & Graduate & $\begin{array}{l}\text { National government } \\
\text { and industries }\end{array}$ & Successful strategy and execution \\
\hline $\begin{array}{l}\text { UK (Cambridge } \\
\text { MIT Initiative) }\end{array}$ & Collaboration between existing institutions & Innovation and entrepreneurship & Graduate & $\begin{array}{l}\text { Shared between the UK } \\
\text { government and MIT }\end{array}$ & $\begin{array}{l}\text { Relatively successful, less than } \\
\text { anticipated spinouts }\end{array}$ \\
\hline $\begin{array}{l}\text { Singapore } \\
\text { (Singapore MIT } \\
\text { Alliance) }\end{array}$ & Collaboration between existing institutions & Boston of the east & Graduate & National government & $\begin{array}{l}\text { Less successful in creating } \\
\text { technopreneurs }\end{array}$ \\
\hline $\begin{array}{l}\text { SkolTech } \\
\text { (SkolTech MIT } \\
\text { Initiative) }\end{array}$ & $\begin{array}{l}\text { Building an institution from scratch and encouraging } \\
\text { collaborations with existing institutions }\end{array}$ & $\begin{array}{l}\text { Boston and Silicon Valley } \\
\text { (innovation and entrepreneurship) }\end{array}$ & Graduate & National government & No reported results yet \\
\hline
\end{tabular}


institutions as a source of strength that allows them to pick and choose from the best practices of world-renowned universities to design and build their own experiment in areas that may be impossible to consider in established universities.

It is worth noting also that the success of Boston's Route 128 or California's Silicon Valley resulted mainly from a bottom-up approach with government support, contrary to many top-down government-directed initiatives that are found in SkolTech and others (Graham 2013; Kinossian and Morgan 2014). For SkolTech also, it is not enough to become a factory for entrepreneurs and start-ups; it is also important that they choose to stay and invest in the region to create long-term impact since for innovation to impact economic growth, it is not as important where ideas first appeared but rather where they are developed (Graham 2013). Brain drain remains a threat to the success of these experiments when outstanding educational outcomes are faced with a lack of economic opportunities (Salmi 2009, p. 73) in the presence of strong international industrial partners seeking the best talents for their own organizations, professors running state-of-the-art research labs and in constant lookout for the qualified graduate students, or venture capitalists seeking a more dynamic and investment-friendly environment to market their products. There are other elements involved in making that choice. According to Roberts and Eesley (2011) in their study of MIT start-ups, the factors that make these companies make their choices about one location versus the other are (1) where the founders lived, (2) contact network, (3) life quality, (4) proximity to major markets, and (5) access to skilled professional workers. Taxes and the regulatory environment were rated as less important factors for most industries. The independent judicial system, intellectual property protection, and the political system that celebrates entrepreneurs and allows dissent voices to rise up did not show up in Roberts' and Eesley's (2011) study because in the US, the presence of these elements is simply taken for granted. These elements partly or collectively are needed for real gradual reform (Graham 2013, pp. 162-164) in addition to what we discussed in the previous sections for innovation and entrepreneurship to flourish and make a dent in the socioeconomic system. This adds more dimensions to consider when analyzing the entrepreneurial ecosystem and goes beyond the scope of this study.

\section{Towards an operational framework for building world-class universities}

In their attempt to jump-start their economies in the knowledge-based entrepreneurial arena and create zones like Boston or the Silicon Valley, governments in different parts of the world opted to start building world-class universities from a clean slate (Rasem and Hassan 2011; Saltykovsky 2013). Creating new institutions offers the opportunity to pick and choose both talented students and staff (faculty and admin cadre) and build regulatory set of rules and incentives to organically create and grow a new culture conducive to what the new institution aspires to accomplish. This is not so easy as it may seem to be. It has cumbersome challenges including but not limited to attracting and keeping the niche spectrum of students and staff to a brandless institution (Salmi 2009, p. 9) which does not obey the tactic of 'if you build it, they will come' (Clary and Karlin 2011). In addition, this undertaking is a costly one and could result in distortion of the resource allocation system of the higher education ecosystem in the country (Salmi 2009, p. 13). Eventually, many countries like Malaysia, Dubai, France, and Norway have spent millions on such an approach and failed, while some like India, Israel, Singapore, 
and China have degrees of success in their quests which brings the question of how Russia would fit along that continuum (Graham 2013, p. 155).

Before going further into what it takes to build a world-class university (WCU), let us define what it means. According to Salmi (2009, p. 5), WCUs are those institutions who achieve superior results in the form of highly sought graduates, leading-edge research, and technology transfer. These results could be linked to three complementary sets of factors found in top universities. They include a high concentration of talent in both faculty and students, abundant resources to support a rich learning environment and to conduct advanced research, and constructive governance features that encourage strategic vision, innovation, and flexibility that enable institutions to make autonomous decisions and to manage resources without being burdened by high bureaucracy (Salmi 2009, p. 7). The relationship between these factors is dynamic, and when aligned as shown in Figure 1, they create virtuous reinforcing loops that could lead to reaching the status of a WCU (Salmi 2009, p. 31).

We explicitly reveal these feedback loops and their interactions using the systems thinking feedback loops representation (Wright and Meadows 2012) in Figure 2.

In the diagram, the $(+)$ sign shown at the tip of the arrows means an increase in a variable leads to an increase in the linked variable and vice versa, and the (-) sign means an increase in one variable leads to a decrease in the linked variable and vice versa. Reinforcing feedback loops occur when an action ( increase or decrease in a variable) creates a result which influences more of the same action thus resulting in growth or decline behavior. They are denoted by the letter $\mathrm{R}$, followed by the loop number (e.g., R1). Resource abundance in the presence of favorable governance that provides autonomy and academic freedom helps attract top faculty who attract students, hence concentrate talent. Concentrated talent and the abundance of wellallocated resources due to favorable governance help performance to flourish (Salmi 2009 , p. 31) which enhances the reputation of the university and its ability in the presence of active leadership to attract more resources in the form of grants, gifts, or invention royalties (Salmi 2009, p. 24), resulting in more resources and better spending ability, and the cycle continues (loops R1 and R2). Improved performance and reputation attract talent (Jump 2014) (loop R3). It has also been reported that highperformance universities have more management autonomy (Salmi 2009, p. 31), hence the positive causal link between performance and favorable governance and vice versa (loop R4). It is important to notice how favorable governance acts as a necessary element in starting up and sustaining the virtuous loop to bring the university to a worldclass status (Salmi 2009, p. 38), facilitating performance, attracting talent, and making better utilization of resources as shown by loops (R4, R5, R6). Any lack in the above three factors will kick a vicious cycle of deterioration and decline. These generated loops could result in either continuous growth or decline in performance, and nothing in between which may overlook other interesting modes of behavior resulting from the mere fact that there are time delays involved between each action and the consequences associated with it (Senge 1990). Time delays here include the time to attract and hire faculty and enroll students, build facilities, make spending decisions, conduct research, graduate students, and commercialize technologies to name a few. These time delays become visible when representing the loops in a more detailed fashion using the system dynamics modeling icons and connections featuring stocks 


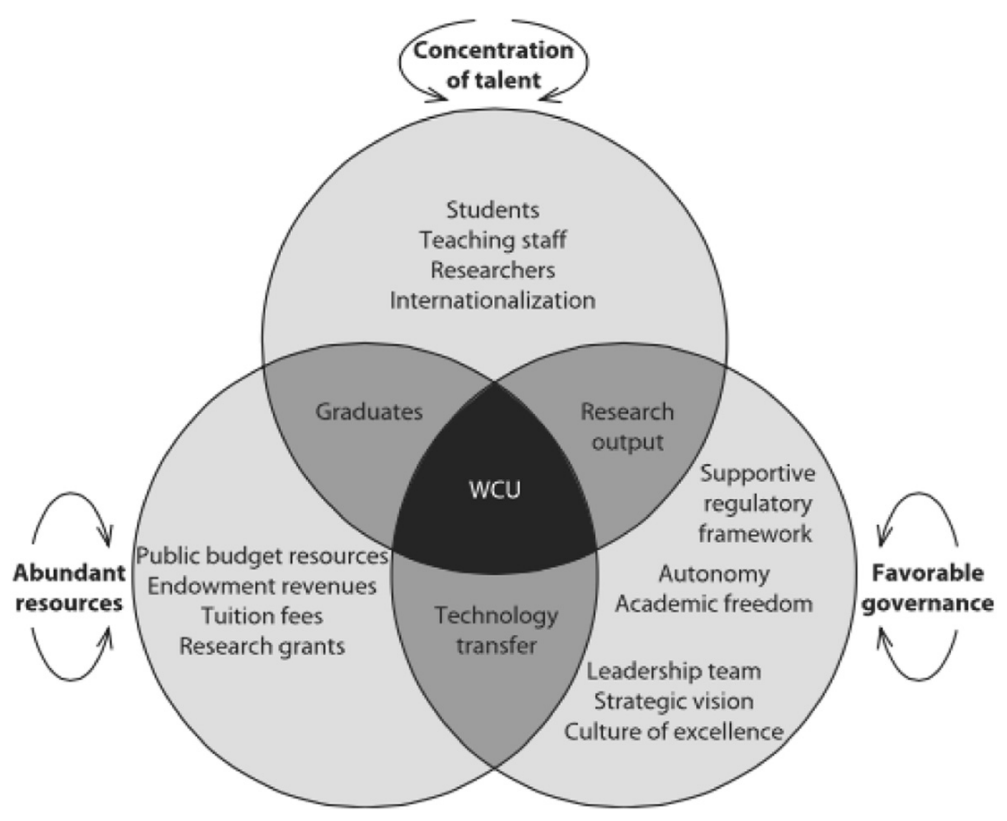

Figure 1 Characteristics of a world-class university (WCU): alignment of key factors, ref. (Salmi 2009, p. 32).

and flows (Forrester 1958, 1961). Flows represent quantities that change over time and stocks represent the accumulation and depletion of these quantities over time. Table 2 Saeed (2008) summarizes the icons and the processes they represent in a typical system dynamics model where the rectangle represents a stock that integrates the flows connected to it and the valve-like icon represents a flow which is the rate of change associated with a stock which may have more than one flow connected to it.

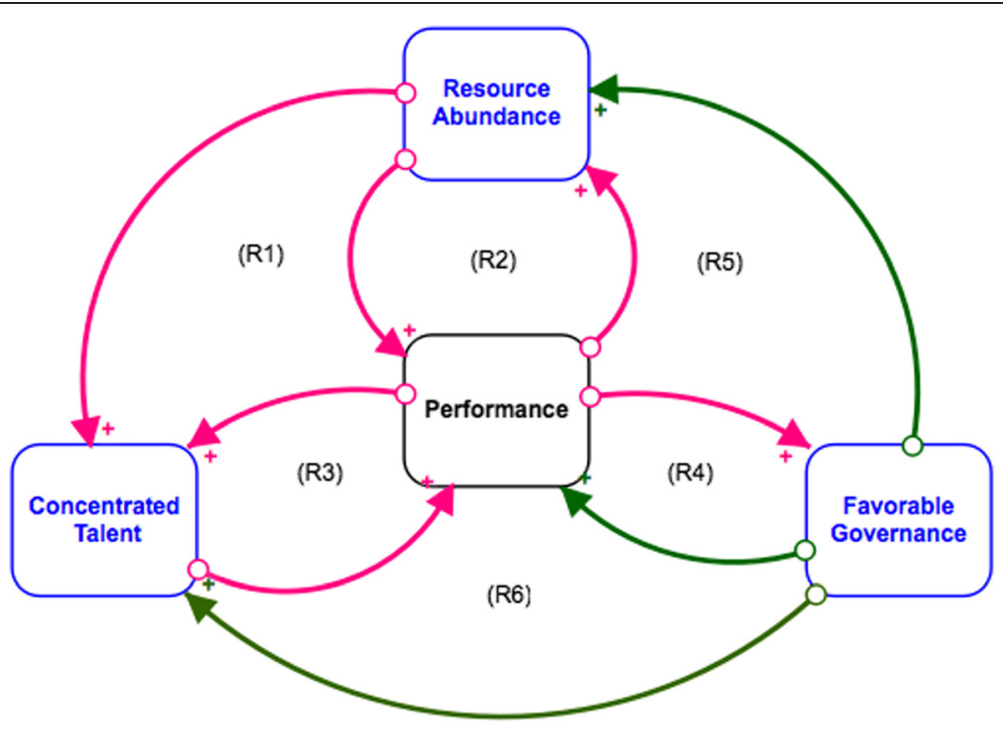

\section{World-Class University}

Figure 2 Dynamic representation of the reinforcing loops generated by the alignment of Salmi's (2009) key factors for creating a WCU. 
Table 2 Icons used for representing model relationships, ref. (Saeed 2008)

\begin{tabular}{ll}
\hline Process & Explanation \\
\hline Stock & Accumulation or integration of flows linked to the icon \\
Converter & Algebraic function of stocks, other converters, and constants \\
Graphical function & $\begin{array}{l}\text { A rate of change or a derivative of a stock. Empty arrowhead } \\
\text { indicates normal direction of flow. Normally connected to a stock. }\end{array}$ \\
Causal link & Information relationship between two variables
\end{tabular}

A stock and flow with a dynamic feedback representation of Salmi's (2009) factors shown previously in Figure 1 is exhibited in Figure 3.

This high-level diagram shows how the factors are intertwined and also shows the complexity of the issue and its dynamic nature. Hence, despite having the right people and the right resources and governance structures, performance will take time to materialize (Salmi 2009, p. 72) and be realized both at the national and international realms. This could create difficulties in realizing the dream especially when governments have sky-high expectations to be realized over a short time horizon.

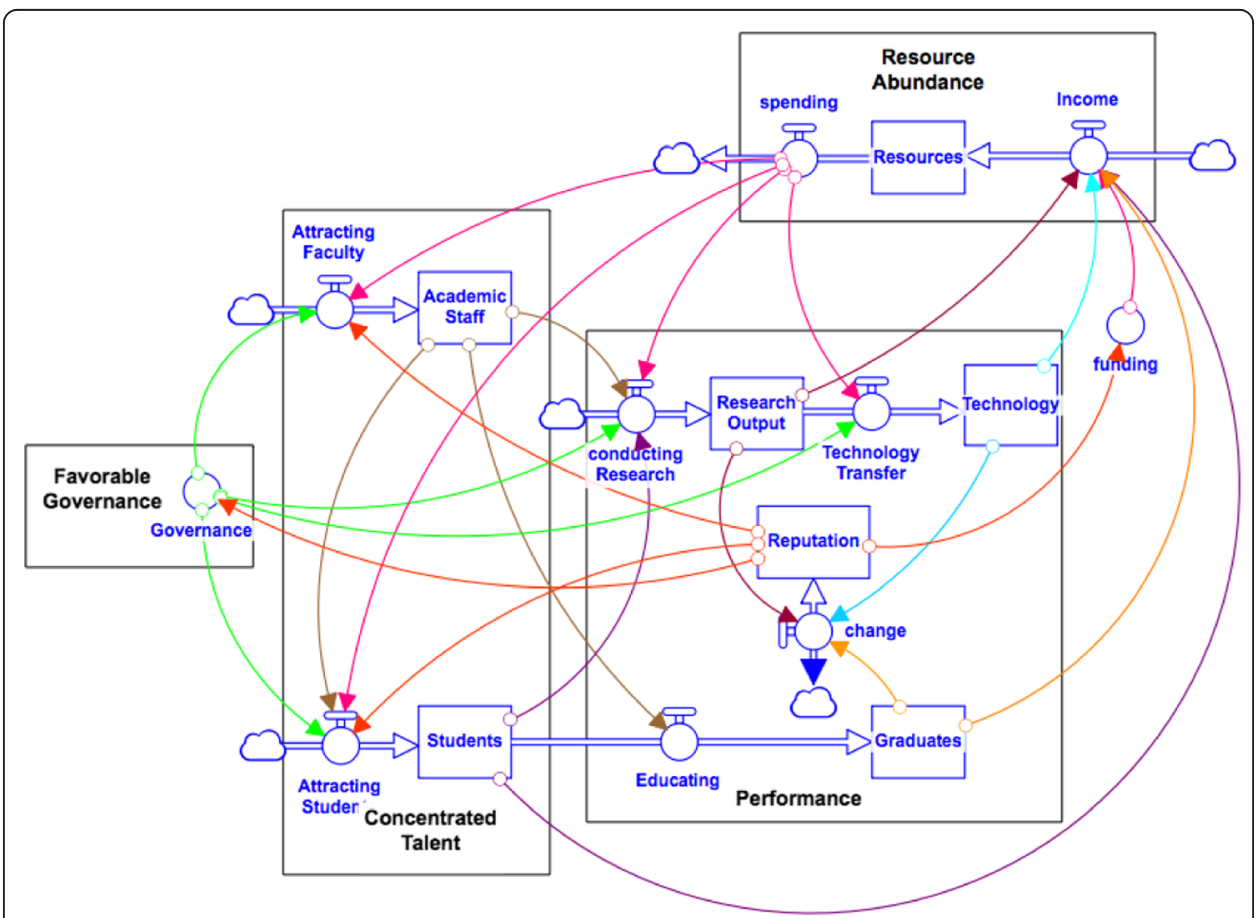

Figure 3 Stock and flow with feedback representation of Salmi's (2009) factors driving the creation of a WCU. 
Salmi (2009, pp. 10-11) also delineates a set of 16 strategic questions supporting the three elements which governments and institutions need to think about and have answers for before embarking on establishing universities of this sort. The questions cover a wide spectrum of issues both at the macro and micro levels ranging from the economic rationale of the initiative and the government's role in it to the target student population, and how quality and success will be measured. The toughest of them all is the following one: does the country need to create a WCU to achieve its economic development aspirations or are there alternative and less costly approaches that could be more effective and require less time to achieve? (Salmi 2009, p. 13). Answering these questions would help in building sound strategies for the institutions and the higher education system in their respective countries.

The three key factors involved in creating a WCU which are further expanded in the form of these strategic questions could lead to the formation of a strategy framework. Our study can be viewed as an operational implementation of the factors and their related strategic questions with a focus on SkolTech. It is crucial to consider, reflect, and debate over the questions and their answers, yet it is equally important to understand their dynamic nature and how they are interconnected and relate to the final goal. Using the stakeholder value analysis (SVNA) to quantify the value delivery network between SkolTech and its major stakeholders and by constructing the strategic architecture (Warren 2008) of the institution using system dynamics modeling and simulation methodology (Sterman 2000), we unravel how the factors and the related questions and their answers interconnect and influence each other over time and create an experimentation and learning canvas for the new institution as it progresses towards accomplishing its goals. We acknowledge the role of favorable governance in making or breaking such an undertaking as emphasized in the higher education, innovation, organizational, and system dynamics literature (Graham 2013; Saeed 1998; Salmi 2009; Zaini et al. 2014). Our study assumes the existence of an effective and inclusive governance for SkolTech, and hence, incorporating governance goes beyond the scope of work; however, it will be incorporated in a future and more generic framework. We also do not explore the economic rationale behind building SkolTech nor why the Russian government chose to build a new institution in addition to upgrading or merging existing institutions in it.

Our work will address architecting SkolTech which shares many WCU attributes discussed by Salmi (2009) like size, student and faculty talent locally and internationally, degree program focus, and funding sources and the like. It will also consider other elements that are not explicitly mentioned by Salmi (2009) like partnerships which are an essential element to SkolTech and to many international universities.

\section{Architecting SkolTech}

Enterprises, much like products, must be architected as complex integrated systems consisting of people, technologies, processes, and information components in order to achieve higher levels of performance (D. Nightingale and Rhodes 2004) One of the active research areas within the evolving field of enterprise system architecting is the development of effective performance measures that could serve as leading indicators for success or failure of enterprise architecting efforts. One of the methodologies proved to be effective in testing the dynamic impact of different strategies is simulation 
modeling enabled scenario analysis (Sterman 2006). An effectively designed system that reflects how enabling processes and internal and external stakeholders interact and contribute to organizations' short-term and long-term performance can support enterprise designers in ongoing architecting and strategic decisions.

Per its mission, SkolTech strives to excel in three main domains: research, education, and innovation. To sustain the development of world-class capabilities in all three areas, delivering value to its diverse set of stakeholders will be critical, and the management systems it has in place can play a major role in achieving its strategic objectives. An enterprise succeeds by supporting the objectives of its key stakeholders (Atkinson et al. 1997). Once strategic goals of the organization reflect key stakeholders' needs, aligning the organization's resources to ensure effective implementation of strategic initiatives becomes imperative. An effective performance management system enables managers not only to diagnose progress towards achieving strategic goals but also to promote organizational learning, leading to more effective strategic management.

There are eight agreed-upon managerial purposes for measuring performance: evaluate, control, budget, motivate, promote, celebrate, learn, and improve (Behn 2003). Given the early stages of SkolTech development, where organizational architecture and the strategic direction are still forming, a system that focuses scarce managerial and engineering attention on key performance drivers (Simon 1959) and their contribution to stakeholders' value delivery could enhance decisionmakers' focus as it relates to strategic planning and implementation in a complex and rapidly changing environment.

To better understand how start-up institutions such as SkolTech can most effectively use its resources to meet strategic objectives, this study focused on two primary goals: (1) to identify key SkolTech stakeholders, what outputs from SkolTech they value, and in what way that value is delivered and (2) given the identified value streams and corresponding strategic objectives for SkolTech, to understand the factors that might influence SkolTech's ability to deliver that value, with implications for its strategy and policies.

The study leveraged SVNA and system dynamics modeling methodologies to achieve the goals mentioned above.

\section{Stakeholder Value Network Analysis (SVNA)}

Large public enterprises often have multiple stakeholders who participate in and receive value from the operation of the enterprise. Each stakeholder has its own value or utility objective function, and while some stakeholders' objective functions may be aligned, in other cases, they may be in conflict with those of other stakeholders or even in part with the enterprise itself. Understanding this complex topography of stakeholders and their values and objectives is important to ensure their continuing participation in and contributions to the overall success of the enterprise.

Stakeholder theory arguably dates back some 30 years to Freeman's (1984) work on the roles of multiple actors in the governance and management of complex public enterprises. This spawned a number of critical questions such as the following: 'How are stakeholders identified?', 'How are their needs discovered?', 'How does management adjudicate when inevitable conflicts in stakeholder interests 
arise?', 'How fine-grained should stakeholders be divided?', and 'How can enterprise management judge whether their performance is benefiting stakeholders in the most efficient or effective way possible?' We build upon more recent work on stakeholder analysis (Cameron et al. 2008; Nightingale Deborah and Srinivasan 2011; Rebentisch et al. 2005) to focus on answering these questions in a rigorous but applicable fashion.

A formal stakeholder analysis founded on qualitative derivation of key stakeholder needs objectives and quantitative breakdown of major value flows between stakeholders and the enterprise. It can reveal insights into how to prioritize strategic objectives of the organization in a way that maximizes shared value delivery to the stakeholders and therefore contributes to the sustained success of the initiative. In their work on stakeholder value network modeling, Cameron et al. (2008) developed a framework for developing stakeholder networks to represent complexity of value delivery, prioritizing system goals, and linking value network models to architectural models. They also proposed that the organizational value outputs should be traced to responsibilities, processes, and incentives dominant in the organization.

As we applied this framework to the stakeholder analysis of the greater SkolTech enterprise, we sought to answer these questions: 'How can we architect a public enterprise that must accommodate numerous (possibly conflicting) views and ideas about how it should achieve its defined mission?', 'Who are the stakeholders?', 'How can we gain insight into their interests and values?', and 'How can we simultaneously address what are certain to be conflicting interests and values among the various stakeholder groups?'

The overall process we used to answer these questions, based on the foundational works summarized above, included the following:

- Identify stakeholders

- Identify needs (inputs) and value delivery (outputs)

- Identify value flows

- Connect value delivery (outputs) to needs (inputs)

- Prioritize flows

- Analyze the stakeholder value network (SVN)

The objective of this analysis is to identify a prioritized list of specific enterprise outcomes that maximize the benefit to the strategic stakeholders. This list of outcomes would form the basis for an enterprise strategy that emphasizes the delivery of those outcomes. We interviewed 28 experts in 12 domains to understand their needs and priorities. The stakeholder value network analysis (SVNA) identified the top priorities for the system, which were used in the construction of the model. Space does not permit elaboration on the SVNA results in this paper.

\section{Modeling the start-up dynamics of SkolTech}

Once the enterprise strategy has been developed, the natural question is whether any of the envisioned or proposed enterprise architectures are likely to produce the desired strategic outcomes. Because SkolTech is in its nascence, it is too early to document outcomes. Consequently, we undertook a modeling and simulation effort to study the 
impact of strategic initiatives, resourcing policies, and incentive structures on the dynamic development of SkolTech and its ability to deliver value to its key stakeholders.

We developed a system dynamics model of the SkolTech enterprise to model the dynamics of a start-up university, leveraging existing systems dynamics methodology (Forrester 1961) to provide decision-makers with appropriate tools to understand the feedback loop structure underlying organizational performance which involves growth and depletion of resources over time and to identify alternative strategies to improve it (Morecroft 2007; Warren 2008).

The modeling effort was conducted to

- Define the current state of SkolTech's performance based on objective measures and benchmarking analysis

- Define the desired future state of SkolTech based on leadership projections and stakeholder expectations

- Identify key factors contributing to SkolTech's ability to achieve the future state and deliver value to its most salient stakeholders

- Develop a simulation model that captures the impact of resourcing policies, incentive structures, and strategic initiatives on SkolTech's short- and long-term performance

The SVNA provides guidance for the development of a strategy for an organization that emphasizes goals, means, and ends that focus organizational and leader attention on the key stakeholders and their value interests that had been identified. In the case of SkolTech, a strategy might be informed by the analysis covered in this paper. But a well-posed strategy must eventually be implemented. In the implementation, the robustness and depth of a strategy is tested and potential gaps and weaknesses revealed. SkolTech is on an emergent path that will take many years to unfold and reveal whether the path chosen was the best possible. Even small course corrections in the early stages of strategy implementation could have large and beneficial impacts later on. Given the potential payoffs, is it possible to test a strategy to identify its gaps or weaknesses prior to its full implementation? Is it possible to use this kind of perspective to fine-tune a strategy to better address any potential challenges?

In this section, we study the impact of strategic initiatives, resourcing policies, and incentive structures on the dynamic development of SkolTech and its ability to deliver value to its key stakeholders. We employ system dynamics modeling methodology (Sterman 2000) to do the following:

- Define the current state of SkolTech's performance based on objective measures and benchmarking analysis

- Define the desired future state of SkolTech based on leadership projections and stakeholder expectations

- Identify key factors contributing to SkolTech's ability to achieve the future state and deliver value to its most salient stakeholders

- Develop a simulation model that captures the impact of resourcing policies, incentive structures, and strategic initiatives on SkolTech's short- and long-term performance

- Test different scenarios to identify potential unforeseen challenges to the strategy 
We used as primary data sources the strategic plan developed by SkolTech and the SVNA cited in this study. We obtained more detailed resource plans aligned with the strategy from SkolTech that provided an early glimpse into how SkolTech intended to organize itself to meet the strategy and its goals. We also accessed public documents describing SkolTech, its mission, organization, and general overview. This modeling effort was intended as a high-level exploratory model to complement the stakeholder analysis rather than a detailed stand-alone predictive model. It is suitable for identifying issues for further study and modeling but should not be used as a decision-making tool.

In its strategy document, the SkolTech mission is to create impact through innovation and partnerships. It aims to accomplish that mission by building a community of 200 faculty members and 1,200 students, with many more post docs and staff. It will have economic and intellectual impact in the Russian Federation by accelerating entrepreneurship across a number of different sectors. The strategy goes into further detail on the specifics of how SkolTech will accomplish these goals. These emerging details provided the necessary background and specific targets to develop a model of the start-up dynamics at SkolTech. The intent behind building this model was to test the SkolTech goals to determine whether any specific challenges existed within the strategy itself or within the context in which it was to be implemented.

The system dynamics model that was created was tailored to the specific setting and aspirations of SkolTech but was based on accepted elements of models of academic institutions (Zaini et al. 2013), other organizations (Warren 2008), and frameworks drawn from prior research and academic publications (Salmi 2009). As such, it was possible to quickly develop a model from existing elements, with the primary risks in the model development being the integration of the various parts into one functioning model, and its accuracy in describing SkolTech specifically.

\section{Start-up research university growth model}

In start-up research universities focused on technology and innovation, performance is paramount to fulfilling their aspirations to become world-class academic institutions. We attempt here to summarize the major elements contributing to the performance of start-up research universities and the dynamic relationships between them. To help simplify matters, we grouped similar elements sharing similar causal relationships with others and created a multilevel dynamic hypothesis in pursuit of insights that improve our understanding of key performance enablers and the strategic management decisions to realize them.

SkolTech shares the major attributes of international start-up universities. As shown in Figure 4, they often start with generous budgets sponsored by their local governments or nonprofit private foundations. They tend to sign up with world-renowned institutions with the intent to jump-start their performance in terms of reputation, supply of innovative research projects, and attracting high-caliber academics. The hope (curves in solid line) is that the performance continues to grow to fulfill their aspirations to be world-class institutions with high economic impact in their regions, grow their academic cadre to reach their designed size, sustain and attract more partnerships, and ultimately be financially viable by at least managing to reach financial equilibrium (Cosenz 2014) despite their enormous start-up expenditures. The fear (curves in dotted line) is that performance does not pick up or in the worst case stagnates or even 


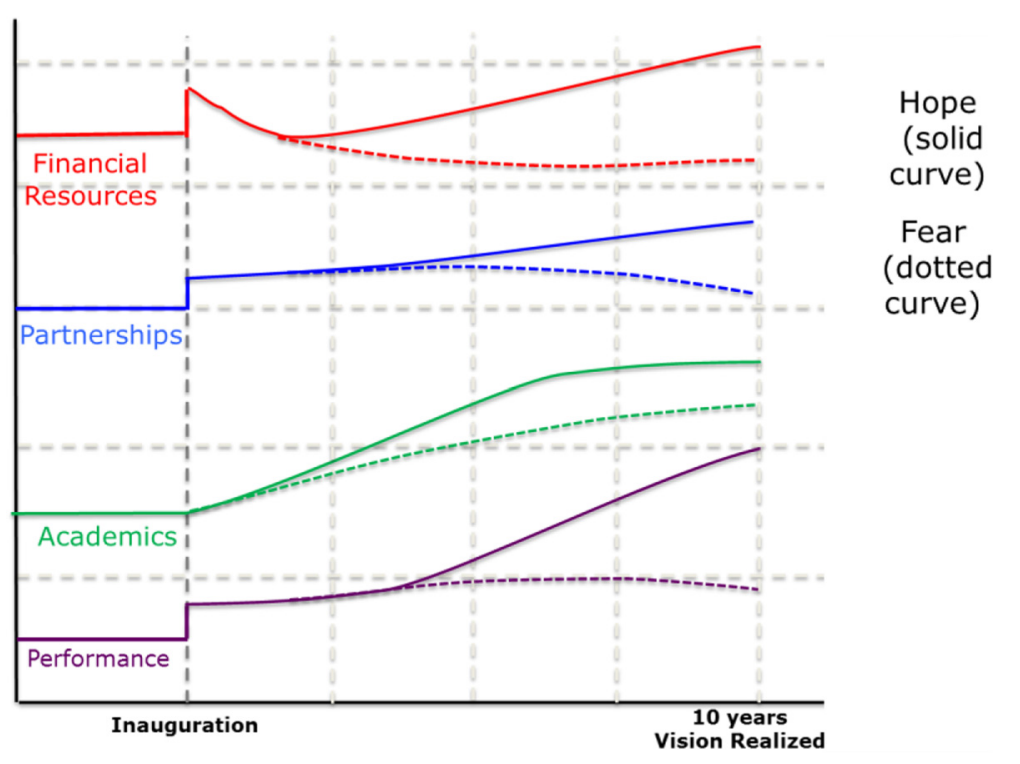

Figure 4 Reference mode diagram showing the major elements contributing to the start-up university performance.

declines. Losing partnerships with other institutions, not to mention growing them further, is another fear scenario. The inability to attract faculty and students or to build the research facilities at the required pace is another fear. Finally, depleting the financial resources is a major source of fear for such institutions. This top-level story and some of the details behind it provide an overall framework of the issues facing a start-up university and can be represented in a multilevel dynamic hypothesis.

In the following section, we attempt to explore key feedback loops influencing both short- and long-term performance of SkolTech.

\section{Key feedback loops driving SkolTech performance}

Performance measures in a university could be short-term focused on tangibles like published papers, generated patents, developed and commercialized innovations, and obtained external grants, or long-term emphasizing strategic indicators like reputation, ability to attract quality faculty and students, and economic impact (Salmi 2009; Zaini et al. 2014). It is important to realize, though, that performance measurement is an integral part of a wider strategic management activity aimed at achieving a sustainable development of the academic institution (Cosenz 2014). At the same time, organizational effectiveness often depends on both the quantity and the quality of its outcomes (Jain et al. 2010). SkolTech management needs to cater to stakeholders with different expectations that fall into both the short-term and long-term categories. SkolTech's ability to produce educational, scholarly, and economic impact is determined in a large part by the quantity and the quality of its students and faculty. Figure 5 shows a causal loop diagram (Sterman 2000) that demonstrates key feedback loops driving SkolTech's performance from the students and faculty side. In the diagram, as explained earlier, the (+) sign shown at the tip of the arrows means an increase in a variable leads to an increase in the linked variable and vice versa, and the (-) sign means an increase in one variable leads to a decrease in the linked variable and vice versa. Reinforcing feedback 


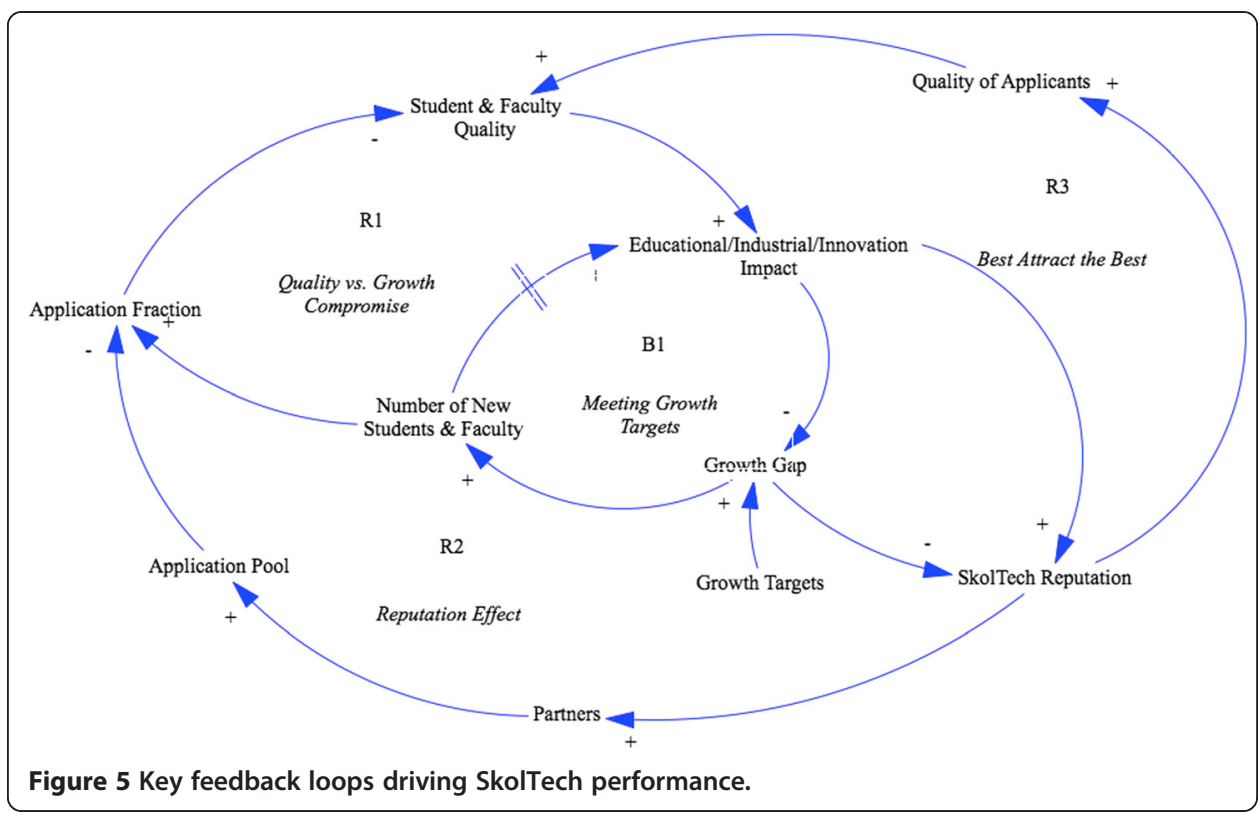

loops are where an action creates a result which influences more of the same action, thus resulting in growth or decline, and are indicated by the letter $\mathrm{R}$, followed by the loop number (e.g., R1). Balancing feedback loops, on the other hand, represent actions that attempt to achieve a goal and close the gap between the current state and the objective and are indicated by the letter (B) followed by the loop number (e.g., B1).

As SkolTech fulfills its growth targets and makes significant educational, industrial, and innovation impacts (albeit with considerable delay), the pressure to rapidly grow its faculty and student populations subsides, which reduces incremental increases in impacts and completes the intended balancing feedback loop (B1). SkolTech's ambition to grow rapidly has the potential of diluting the quality of its graduates and faculty. If the growth of the application pool does not keep up with the need to grow the student and faculty population, acceptance fraction will increase, negatively impacting the quality (Salmi 2009, p. 21) and triggering a vicious cycle of further growth reinforcing quality and impact deterioration (loop R1). Educational, industrial, and innovation impact in part drives SkolTech's reputation. As SkolTech's reputation becomes more widespread and known to its Russian and international partners, faculty and student application pool increases, which improves the quality of SkolTech's main assets: students and faculty (loop R2). SkolTech's reputation is a key determinant of SkolTech's success as it drives both the size of the application pool and the quality of applicants (Leslie and Kargon 2006), which trigger either virtuous reinforcing cycles of growth and impact or vicious cycles of epic collapse (loop R3).

There are missing elements in this conceptual framework like educational programs, marketing and public relations campaigns, and the administration overhead. Their contribution to the performance and how they relate to the existing elements are yet to be explored.

\section{A model of SkolTech}

The performance causal loop diagram (Figure 5) was developed into a more detailed and executable system dynamics model of SkolTech using iThink ${ }^{\circ \mathrm{d}}$ modeling software. 
The first step was to identify the major stocks (accumulating quantities) and flows (rates that drive the accumulation or depletion of accumulated quantities) in the model, which correspond to the variables discussed previously. An aggregate-level representation of the model showing major stocks and flows is shown in Figure 6.

The three stock and flow pipelines govern the growth of internal resources (Warren 2008) of SkolTech: students; faculty, which Salmi (2009) refers to as talent; and facilities. Research production is driven in a large part by SkolTech's internal resources. SkolTech's reputation, summing its performance, is another important stock that grows gradually as a function of educational, economic, and innovation impact. Available budget's growth is dependent on SkolTech's ability to meet key stakeholder expectations which are imbedded in SkolTech's reputation. Key partnerships grow as a function of SkolTech's reputation. The strength of SkolTech's partnerships subsumes the number and the quality of prospective faculty and students as well as the size of available budget. High-quality students and faculty improve both the alumni quality and innovation impact, hence improving reputation, partnerships, and both the quality and numbers of students and faculty (loop R1). A strong financial status helps accelerate hiring faculty and enrolling students, in addition to research progression and facility construction which in turn grows reputation and partnerships to further enhance its ability to receive funding in the form of grants or gifts (Salmi 2009, p. 24) and hence improves its financial status (loop R2).

From these stocks and flows, the model was created along major sectors, each representing a primary element of the system. These include faculty, students, facilities, partnerships, and research teams. Additionally, outcomes such as impact, reputation, and quality had their own sectors with corresponding models. Financial sector represents a major constraint in the university and allows testing of resource allocation decisions in

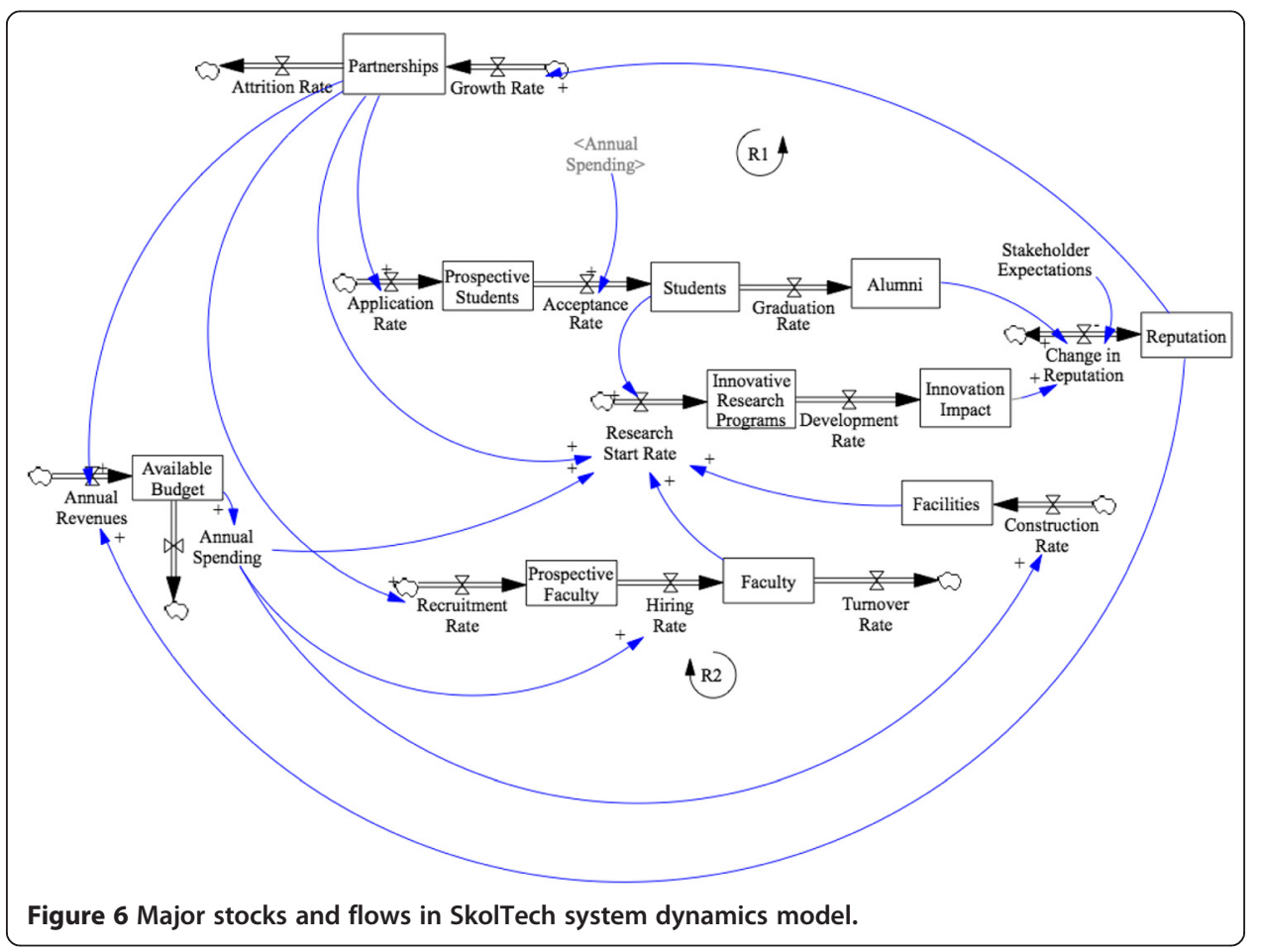


the model that could influence the overall growth trajectory. An overview of the model sectors, left unconnected to simplify the view, is shown in Figure 7. As shown in the figure, the degree of detail captured by the many variables begins to expand quickly.

A high-fidelity model was developed with over 140 variables. Many of the elements of the model are based on existing system dynamics model functions found in existing publications in the area of system dynamics applications in strategy modeling and simulation (Salmi 2009, p. 24). Sharing the full details of the development, the structure, the testing, and the outcomes of such a model is beyond the scope of this paper. The baseline case for the SkolTech model was built using input data from the strategic plan and other SkolTech documents. The model with all relationships and variable values from the documentary evidence was then calibrated to the outcomes envisioned in the strategy - the baseline model assumes that the inputs and parameters specified in the strategy produce the outcomes also specified in the strategy. This does not include common performance-limiting factors like organizational complexity, change resistance, or disturbances from the external environment (Warren 2008). This means that it is able to reproduce the envisioned rates of growth of students, faculty, facilities, etc. The output graphs of the baseline model are shown in Figure 8. In the figure, the blue curves represent the growth targets specified in the strategy, while the red curves are the model output. It can be seen that the model is able to closely track the strategy. The model also provides the growth rates necessary to reach the specified targets in the form of operational policies like annual class size, faculty hiring rates, and facility construction rates.

While it is a significant feat to produce a model of this complexity, at some point, it is not necessarily revealing any new system-level insights since the model is only producing the output of the framework that it was designed upon. There are of course

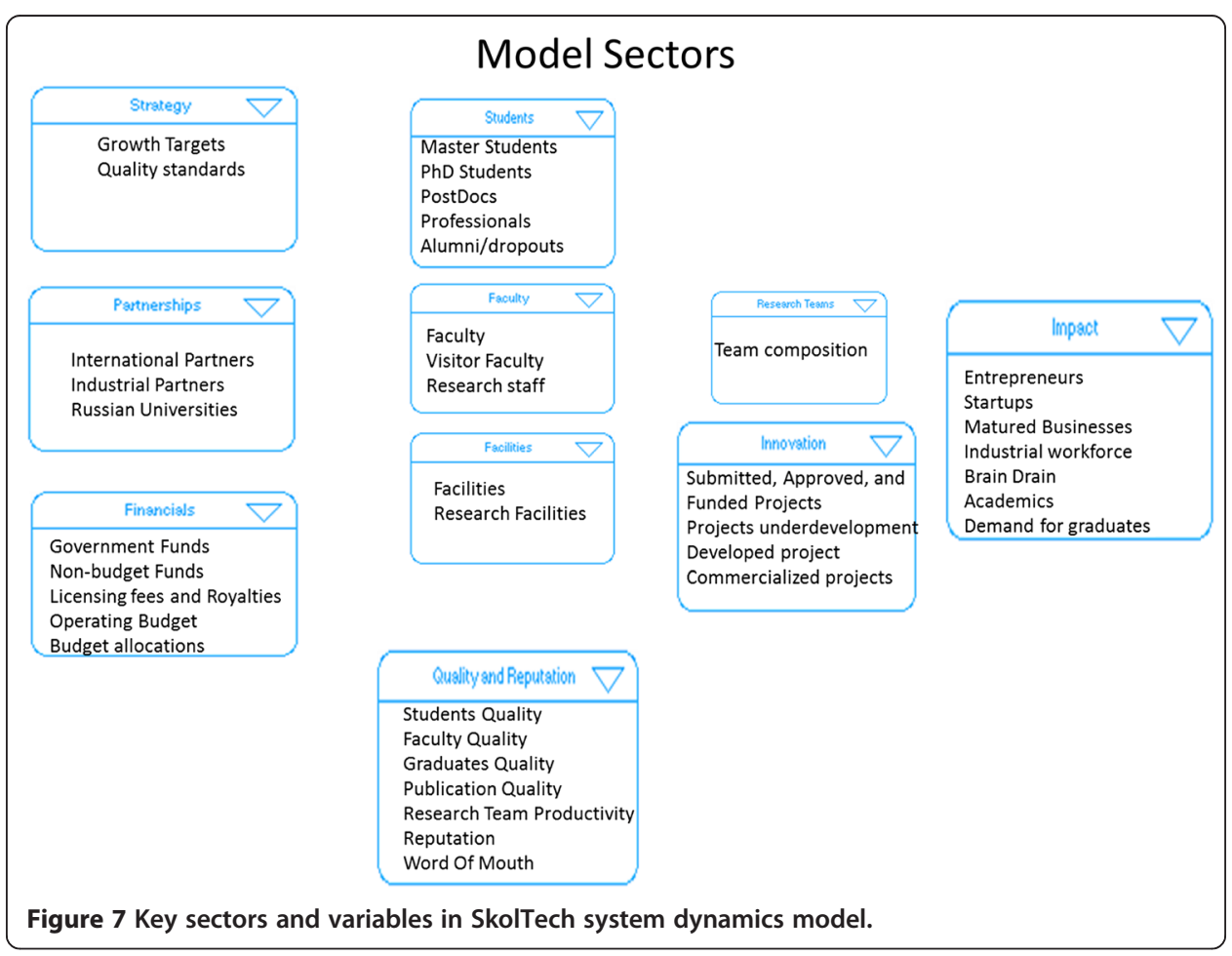




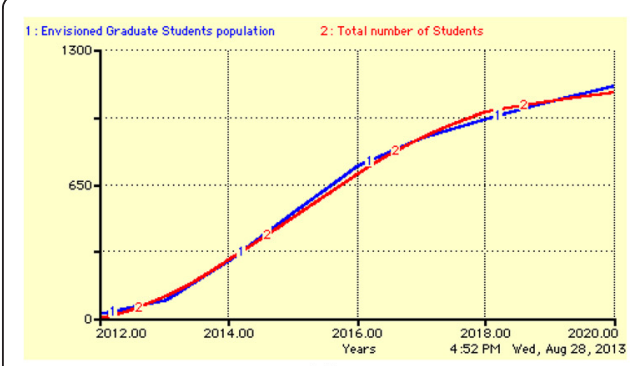

(a)

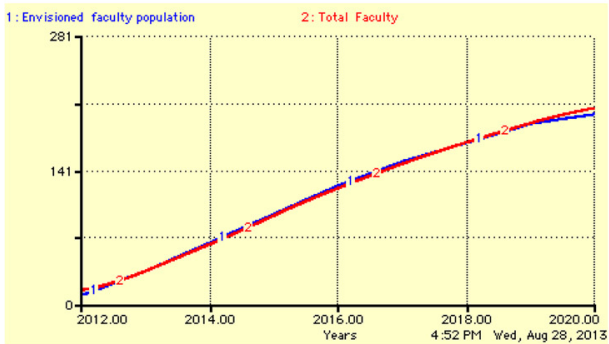

(b)

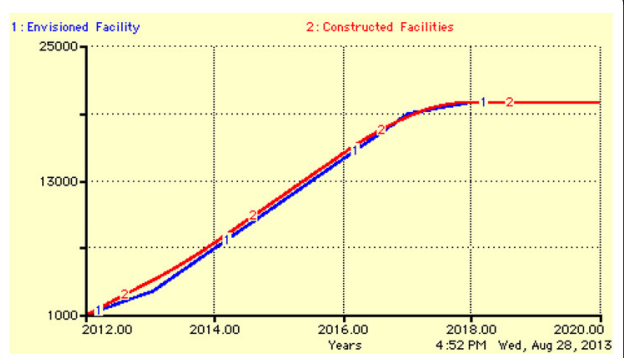

(c)

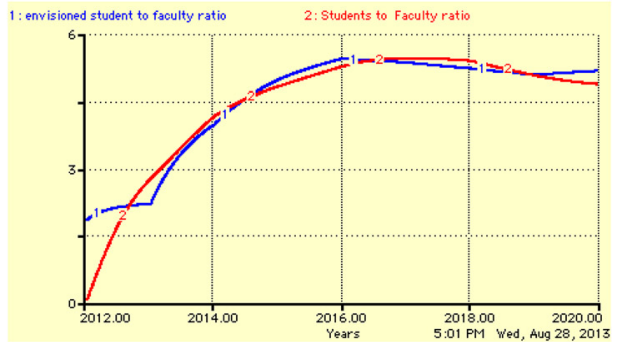

(d)

Figure 8 Model base case outcomes for (a) graduate students, (b) faculty, (c) facilities, and (d) student to faculty ratio.

more detailed outcomes at the level of individual variables, but those variables were not necessarily developed through an extensive empirical process unique to a new institution like SkolTech, so they mostly describe how generic elements of a start-up university are thought to behave based on the literature (Salmi 2009), documentation of other universities during start-up phases with which SkolTech shares many attributes and/or where MIT had direct involvement (Cosenz 2014; Leslie and Kargon 2006; Mervis 2012).

Despite these caveats, the model is still useful in that it is logically correct, and functionally consistent both with itself (i.e., it operates as a stable system through an acceptable and useful range of variation in key variables) and with other published models. Consequently, we expect it to resemble the behavior of a start-up university at a first approximation. It furthermore becomes more useful for generating insights as it is perturbed away from the baseline case operating modes upon which it was designed.

\section{Scenario analysis}

To develop insights into possible challenges that SkolTech might face under 'off-design' conditions with respect to its strategy, major constructs in the system model were varied outside of their intended range. Specifically, since one of SkolTech's strategic goals is to be a leading global institute of science and technology, we asked what would happen if it were forced to relax its standards for quality of students, faculty, work, and output pressured by the growth expectations. This represents 'case 2', where quality standards are reduced, reputation suffers correspondingly, and a vicious cycle of lower quality of students and faculty leads to less demand for graduates, lower quality of research papers, and higher chance of start-up failures, all contributing to lower reputation which attracts lower quality students. In 'case 3', in addition to these quality and reputation declines, we also impose financial constraints to varying degrees. In all cases, 
we monitor key constructs such as the number of students, faculty, impact, research and innovation output, etc. The top-level findings of these scenarios (compared with the base case) are shown in Table 3.

While some of the findings of the scenario analysis are intuitive (e.g., reducing quality of students results in lower demand from industry for graduates), others are not (e.g., imposing a tight budget increases demand for graduates $\left.{ }^{\mathrm{e}}\right)$. This is not an unexpected outcome for a model as large and complicated as this - it demonstrates a nonlinear behavior in some scenarios. This behavior could be represented by simulation charts and can be systematically traced by highlighting all the active feedback loops, but this goes beyond the scope of this paper. In general, it is the application fraction that is reduced and hence kicks in loop R1 that restores reputation and hence improves the applicant pool as shown in Figure 5.

This is not necessarily due to faulty model building and in fact can flag the sort of reaction for which this model was intended. A classical strategy development exercise is generally driven top-down and based on assumptions of linear behavior. Developing and experimenting with a dynamic model such as this can operationalize frameworks (Salmi 2009) to help planners put to test their intentions and reveal the limitations of linear behavior assumptions. The weak elements in the strategy can be exposed and flagged for examination in greater detail through other means.

\section{Conclusion and future work}

Nations put research universities at the heart and center of their efforts to transform their economies to become more innovative and entrepreneurial. The Russian government took a bold step in partnering with MIT to create the SkolTech. MIT has a rich experience in playing a role of a key partner in establishing similar institutes around the world for the past 50 years, with differing degrees of success and economic impact. The variation in outcomes was influenced by a multitude of factors including (1) the

Table 3 Scenario analysis outcomes

\begin{tabular}{|c|c|c|}
\hline $\begin{array}{l}\text { Case } 1: \\
\text { base case }\end{array}$ & $\begin{array}{l}\text { Case 2: active quality and reputation } \\
\text { impacts }\end{array}$ & $\begin{array}{l}\text { Case 3: active quality, reputation and } \\
\text { budgetary impacts }\end{array}$ \\
\hline Graduates & $\begin{array}{l}\text { Number of students and graduates did not } \\
\text { change as there was no influence of the drop in } \\
\text { quality on student dropouts and lower quality } \\
\text { standards allow for a higher funnel of students } \\
\text { being admitted }\end{array}$ & $\begin{array}{l}\text { Drop in the number of students and graduates } \\
\text { as financial limitations become effective around } \\
2017\end{array}$ \\
\hline $\begin{array}{l}\text { Faculty/ } \\
\text { Staff }\end{array}$ & $\begin{array}{l}\text { Drop in academic staff since quality drop } \\
\text { impacts the number of faculty getting tenure } \\
\text { and reputation drop also impacts the ability to } \\
\text { hire visitor faculty and research staff and also } \\
\text { weakens the pool of prospective faculty }\end{array}$ & $\begin{array}{l}\text { Turning point in academic staff due to budget } \\
\text { limitations and higher production of } \\
\text { commercialized projects relative to case } 2 \text {. The } \\
\text { limited financial resources could lead to further } \\
\text { deterioration in quality standards of the faculty } \\
\text { and students admitted under the pressure to } \\
\text { hit performance and budgetary targets. Lower } \\
\text { quality impacts research team productivity and } \\
\text { quality of innovation pipeline which prompts } \\
\text { the government to cut budget, even further } \\
\text { reinforcing the vicious cycle }\end{array}$ \\
\hline $\begin{array}{l}\text { Demand } \\
\text { for } \\
\text { graduates }\end{array}$ & $\begin{array}{l}\text { Drop in HR demand by the industry despite } \\
\text { keeping a strong growth of start-ups. }\end{array}$ & $\begin{array}{l}\text { Increase in HR demand due to a decline in the } \\
\text { number of prospective employees and a gradual } \\
\text { increase in the number of start-ups (which } \\
\text { ultimately raises questions about the long-term } \\
\text { sustainability of this scenario) }\end{array}$ \\
\hline
\end{tabular}


degree by which the MIT model was tailored to serve the local context, (2) the ambitious expectations of the governments that are based on the mental model of simply copying Boston or Silicon Valley through generous funding and partnerships, (3) the complexity of the issue and the large time delays involved until entrepreneurial activities could flourish and make a dent in the socioeconomic environment, and (4) the domestic issues beyond the control of a higher education institution influence.

The two-part research study that followed and was summarized in this paper covered part of the effort in architecting SkolTech through a formal stakeholder analysis, strategy modeling, and scenario analysis.

We leveraged the stakeholder value delivery network to derive the most important outputs expected from SkolTech which included production of talent and research necessary to attract and retain patient capital and accelerate innovation in Russia. Analysis of stakeholder expectations, which varied in nature, importance, and time horizon, provided SkolTech's leadership team with important insights from which they developed a 5-year strategic plan.

In the second phase, we focused on testing the strategic plan model formulated on the basis of the institution's strategic vision and the stakeholder analysis revealing several strategic levers and raising more questions that could underpin success or failure of achieving long-term strategic goals. We derived the following insights from our stakeholder analysis and modeling work.

- SkolTech's ability to meet its strategic targets relies in part on its capability to rapidly grow its student and faculty population. Under a few different scenarios, including imposing stricter quality standards in order to boost reputation, or under financial constraints due to slow income growth, it may be unable to meet those planned population growth rates. Whether either of those scenarios is realistic or not is a reasonable topic for a discussion among key stakeholders. However, a shortfall in student and/or faculty populations predictably slows the rate at which SkolTech is able to achieve its broader strategic objectives and as such should be a key area of focus for the leadership.

- There is a clear tension between the pressure to scale SkolTech's impact and SkolTech's ability to attract and retain exceptional talent. As the pressure to increase the impact builds (e.g., through research output, graduates, start-ups, etc.), student to faculty ratios become unfavorable, faculty workload increases, and other factors come into play that would threaten retention of exceptional talent. Failure to retain talent impacts quality, reputation, and ultimately the goal to become a world-class research institution and an economic engine for the Russian Federation.

- The 'chicken and egg' dilemma of needing brand/reputation to attract talent and needing talent to build reputation is addressed at least in part by MIT/SkolTech partnership. SkolTech could build its reputation on its own, but the time lags associated with that approach are significant and might prove to be too much given the rates of change typical of political and economic priorities. By availing itself of MIT's expertise, guidance, and reputation, SkolTech can reduce the time to achieve self-sustaining levels of reputation and thereby accelerate its achievement of its strategic objectives. 
- The enormous time delays needed, as in the case of the Cambridge MIT Initiative and others, for anchoring entrepreneurial activities and having it flourish and cause a measurable change could have a negative impact on government support and sustenance of SkolTech's development trajectory.

The observations based on a model grounded in a framework from the literature (Salmi 2009) but not extensively tested and as such are subject to the limitations of the model itself. The model in its current state can be used to communicate strategic challenges with stakeholders to facilitate a rich conversation. Using the model to dynamically test SkolTech's strategy would call for the next level of rigorous model development. Accordingly, next steps include:

- Validating major modeling assumptions

- Testing the impact of various resource management and macroeconomic scenarios on SkolTech's performance

- Using the model to communicate both strategic and operational challenges and trade-offs with key stakeholders

SkolTech and other start-up research universities remain as experiments worthy of pursuit and sustained support of their stakeholders as they will likely take a considerable amount of time to realize their full potential. It is also important to know that, despite their critical role in driving change through providing the knowledge capital to their nations, they are part of an intricate educational, innovation, and economic system that if fully aligned could make full and expected use of their outcomes or if uncoordinated and in conflict could see their efforts come to naught. It is prudent to closely monitor their progress towards their goals and provide the strategy models with data to validate their structures and tune in their parameters. We think that what we have learned from this study is not specific to SkolTech but could be applicable to other start-up research universities. Therefore, the provided insights would be of value to development planners in their respective countries and to the field of research, innovation, and higher education at large. Formal stakeholder analysis and strategic modeling can be used to operationalize frameworks, test major assumptions, and reveal various pitfalls on the road to building a WCU.

\section{Endnotes}

${ }^{a}$ http://www.skoltech.ru/en/2014/09/meet-the-bot/.

${ }^{\mathrm{b}}$ Industrialist G. D. Birla.

${ }^{c}$ http://www.caltech.edu/content/glance.

$\mathrm{d}_{\mathrm{i} T h i n k}$ is a system dynamics modeling and simulation software from iseesystems.com.

${ }^{\mathrm{e}}$ In this case, the increase in demand for graduates is explained by the ability to be more selective in admissions (despite relaxing quality standards) because there are fewer openings available to the pool of prospective candidates.

\section{Additional file}




\section{Acknowledgements}

The authors wish to acknowledge the financial and research support of the MIT SkolTech Initiative, without which this research would not have been possible. Any errors or omissions are solely the responsibility of the authors and not that of SkolTech or the MIT SkolTech Initiative.

\section{Author details}

${ }^{1}$ Social Science and Policy Studies department, Worcester Polytechnic Institute, 100 Institute Road, Worcester, MA 01609-2280, USA. ${ }^{2}$ Sloan School of Management, Massachusetts Institute of Technology, 100 Main Street, Cambridge, MA 02142, USA. ${ }^{3}$ Sociotechnical Systems Research Center, Massachusetts Institute of Technology, 77 Massachusetts Avenue, Cambridge, MA 02139, USA.

Received: 19 May 2014 Accepted: 10 December 2014

Published online: 27 February 2015

\section{References}

Adam D (2002) Cambridge-MIT Institute probed. Nature 420(6913):256-256, 10.1038/420256b

Atkinson AA, Waterhouse JH, Wells RB (1997) A Stakeholder Approach to Strategic Performance Measurement. Sloan Management Review 38(3):25

Behn R (2003) Why Measure Performance? Different Purposes Require Different Measures. Public Administration Review 63(5):586-606, doi: 10.1111/1540-6210.00322

Cambridge, MIT join forces: Universities promote U.K. entrepreneurship. (1999). The Globe and Mail (1936-Current), p. B14

Cameron BG, Crawley EF, Loureiro G, Rebentisch ES (2008) Value flow mapping: using networks to inform stakeholder analysis. Acta Astronautica 62(4):324-333

Chameau J-L (2013) Innovation is in the air and everywhere else, too. Times HigHer Education WORLD UNIVERSITY RANKINGS 2013-14. pp 38-39

Clary C, Karlin ME (2011) Saudi Arabia's reform gamble. Survival 53(5):15-20

Cosenz F (2014) A Dynamic Viewpoint to Design Performance Management Systems in Academic Institutions: Theory and Practice. International Journal of Public Administration 37(13):955-969, doi: 10.1080/01900692.2014.952824

Etzkowitz H (2002) MIT and the Rise of Entrepreneurial Science (Vol. v. 12). Routledge, New York

Forrester JW (1958) Industrial dynamics: a major breakthrough for decision makers. Harv Bus Rev 26(4):37-66

Forrester JW (1961) Industrial Dynamics. Productivity Press, Cambridge MA

Freeman RE (1984) Strategic Management: A Stakeholder Approach. Pitman Publishing, Boston

Gokhberg L, Meissner D (2013) Innovation: superpowered invention. Nature 501(7467):313-314, 10.1038/501313a

Gokhberg L, Roud V (2012) The Russian Federation: A New Innovation Policy for Sustainable Growth. The Global Innovation Index. p 121

Graham (2013) Lonely Ideas: Can Russia Compete? The MIT Press, Cambridge, Massachusetts

Hsu DH, Roberts EB, Eesley CE (2007) Entrepreneurs from technology-based universities: evidence from MIT. Res Policy 36(5):768-788

Jain, Triandis, \& Weick (2010) Managing Research, Development and Innovation: Managing the Unmanageable. Wiley, Hoboken, NJ Jump IP (2014) Overseas PhD Students Rely on Rankings to Select a University, Times Higher Education

Ka Ho M (2008) Singapore's global education hub ambitions. Int J Educ Manag 22(6):527-546, 10.1108/09513540810895444 Kinossian N, Morgan K (2014) Development by Decree: The Limits of 'Authoritarian Modernization' in the Russian Federation. International Journal of Urban and Regional Research 38(5):1678-1696, doi: 10.1111/1468-2427.12159

Leslie SW, Kargon R (2006) Exporting MIT: science, technology, and nation-building in India and Iran. Osiris 21(1):110-130, $10.1086 / 507138$

Mervis J (2012) Growing pains in the desert. Science 338(6112):1276-1280

MIT, Cambridge join forces: Final Edition. (1999). The Ottawa Citizen, p. J.2

Morecroft (2007) Strategic Modelling and Business Dynamics: A Feedback Systems Approach. John Wiley \& Sons, Hoboken, NJ Newsletter SkolTech (2014). 17. http://www.skoltech.ru/app/data/uploads/sites/2/2014/09/ NEWSLETTER_FIN_ENG_August_September.pdf

Nightingale D, Rhodes D (2004) Enterprise System Architecting: Emerging Art and Science within Engineering Systems, MIT Engineering Systems Symposium

Nightingale DJ, Srinivasan J (2011) Beyond the lean revolution: achieving successful and sustainable enterprise transformation. AMACOM Div American Management Association, New York, NY

Pfotenhauer SM, Jacobs JS, Pertuze JA, Newman DJ, Roos DT (2013) Seeding change through international university partnerships: the MIT-Portugal program as a driver of internationalization, networking, and innovation. High Educ Pol 26(2):217-242, 10.1057/hep.2012.28

Plutocrat Vs. Tech-nocrat (2013) Bloomberg Businessweek., p 3

Rasem NK, Hassan MK (2011) Saudi Arabia's economic development: entrepreneurship as a strategy. Int J Islam Middle E Finance Manag 4(1):52, 10.1108/17538391111122203

Rebentisch ES, Crawley EF, Loureiro G, Dickmann JQ, Catanzaro SN (2005) Using Stakeholder Value Analysis to Build Exploration Sustainability, Paper presented at the 1st Space Exploration Conference: Continuing the Voyage of Discovery

Roberts EB, Eesley CE (2011) Entrepreneurial impact: The role of MIT. Foundations and Trends ${ }^{\oplus}$ in Entrepreneurship 7(1-2):1-149, doi: http://dx.doi.org/10.1561/0300000030

Saeed K (1998) Maintaining professional competence in innovation organizations. Hum Syst Manag 17(1):69-87

Saeed K (2008) Limits to Growth Concepts in Classical Economics., Available at SSRN 806227

Salmi J (2009) The Challenge of Establishing World-class Universities. World Bank, Washington, D.C

Saltykovsky D (2013) Skolkovo: Tech city that aims to restore nation's pride. In: BBC Future., Retrieved from BBC.com website: http://www.bbc.com/future/story/20130827-skolkovo-too-little-too-late

Senge PM (1990) The Fifth Discipline: The art and Practice of the Learning Organization. Currency: Doubleday, New York 
Sidhu R, Ho KC, Yeoh B (2011) Emerging education hubs: the case of Singapore. High Educ 61(1):23-40, 10.1007/ s10734-010-9323-9

Simmonds P, Stroyan J, Clark J (2009) An evaluation of the Cambridge-MIT Institute, Technopolis Group., p 2

Simon H (1959) Theories of Decision-Making in Economics and Behavioral Science, The American Economic Review

Sterman JD (2000) Business dynamics: systems thinking and modeling for a complex world. Irwin/McGraw-Hill, Boston

Sterman JD (2006) Learning from evidence in a complex world. Am J Public Health 96(3):505

Vandre M (2003) From Cambridge to Cambridge (Vol. 106, pp. MIT8)

Warren K (2008) Strategic Management Dynamics. J. Wiley \& Sons, Hoboken, NJ

Wright D, Meadows DH (2012) Thinking in systems. Taylor and Francis, Hoboken, NJ

Zaini R, Hoffman A, Saeed K, Tichenor K, Radzicki M, Pavlov (2013) Strategies for University Growth A System Dynamics Analysis of Organizational Change. Paper presented at the The 31st International System Dynamics Conference, July 2013, Cambridge, MA, USA

Zaini R, Saeed K, Elmes M, Pavlov OV (2014) Dynastic Cycle: A Resource Allocation Theme For Addressing Dissent In Universities. Paper presented at the The 32nd International Conference of the System Dynamics Society, July 2014, Delft, Netherlands

Submit your manuscript to a SpringerOpen ${ }^{\circ}$ journal and benefit from:

- Convenient online submission

Rigorous peer review

- Immediate publication on acceptance

- Open access: articles freely available online

- High visibility within the field

- Retaining the copyright to your article

Submit your next manuscript at $\boldsymbol{\nabla}$ springeropen.com 